\title{
Collective Emotions Supervision in the Product-Servicing Networks
}

\author{
Filipa Ferrada ${ }^{1}$ and Luis M. Camarinha-Matos ${ }^{1,2}$ \\ ${ }^{1}$ CTS, Uninova, Departamento de Engenharia Electrotécnica, Faculdade de Ciências e \\ Tecnologia, FCT, Universidade Nova de Lisboa, 2829-518 Caparica, Portugal \\ ${ }^{2}$ Departamento de Engenharia Electrotécnica, Faculdade de Ciências e Tecnologia, FCT, \\ Universidade Nova de Lisboa, 2829-518 Caparica, Portugal \\ \{faf, cam\}@uninova.pt
}

\begin{abstract}
The GloNet network is an agile virtual enterprise environment for networks of SMEs involved in highly customized and service-enhanced products through end-to-end collaboration with customers and local suppliers (co-creation) in the solar park construction sector. A challenge that arises in this network is the effective management of the interactions among participating organizations and their customers. Some participants' problems, that are not solvable with the working hard procedures of the project execution, might arise leading to some potential tension. Most of the times this tension is a result of soft "emotional" issues experienced in the collaboration "environment". Considering these challenges and having in mind enhancing the quality of the interactions between the involved participating organizations, this paper describes a scenario for supervising collective emotions in the GloNet network context.
\end{abstract}

Keywords: Emotions, Collective Emotions, Collaborative Networks, Productservicing Networks, Collaboration Health.

\section{Introduction}

In the current global and dynamic business environments we have been assisting to a growing trend towards developing highly customized products and services. This assumes the mass customization paradigm of providing individually designed products and services to customers by means of process flexibility and quick responsiveness [1]. Furthermore, besides the physical product, a number of business services add value to the product.

The GloNet network aims to support an agile virtual enterprise environment for networks of SMEs interested in pursuing mass customization businesses through implementing the glocal [2] enterprise notion. This involves highly customized and service-enhanced products through end-to-end collaboration with customers and local suppliers (co-creation).

A challenge in this network is the effective management of the interactions among participating organizations themselves and the customers, namely in what concerns the management of "soft" issues that are not solvable with the hard processes of the 
project execution. These issues can include inter- and intra-organizational abilities, problems in keeping team cohesion, leadership, customers and the network as a whole[3]. It might also include external factors such as the participating organization itself, the people that stand for the organization, etc. In addition, one cannot forget that organizations are composed of people, and people have intrinsically associated emotions which are present in all interactions, so most of the times these conflicts are a result of emotions speaking for themselves. Considering these challenges, it is important to understand these psychological aspects and effectively manage the participating organizations by avoiding emotional conflicts[4].

In this context the main research question is: What could be a suitable set of models, methods and tools to promote emotional health in collaborative networks, namely allowing the diagnosis of the networks' emotional state and assisting in conflicts resolution?

In order to give an answer to this research question, this paper presents a business scenario for supervising collective emotions in the context of the GloNet project. The reminder of this paper is organized as follows: Section 2 identifies the relationship of this work to Internet of Things; Section 3 gives a brief description of the related literature namely the collective emotions in the collaborative networks context, the GloNet network and the characteristics inherent to business scenarios used in this application case; Section 4 presents the business scenario on collective emotions supervision services; and finally Section 5 concludes.

\section{Relationship to Internet of Things}

More than ever, "things" are more actively present in our daily routines either at our homes or at business. According to Sandmaeker et al. [5]Internet of Things (IoT) "is a integrated part of the Future Internet and could be defined as a dynamic global network infrastructure with self-configuring capabilities based on standard and interoperable communication protocols where physical and virtual "things" have identities, physical attributes, and virtual personalities and use intelligent interfaces, and are seamlessly integrated into the information network".

In product-servicing collaborative networks IoT might be applied through embedding smart devices able to interact and communicate among them and with the environment by exchanging data and information and reacting autonomously to events (e.g. the data exchanged by the embedded sensors in the solar plant help in the optimization of processes, refinement of schedules, improvement of logistics, etc.).In such networks, the communication, which may be remote, between participants (people on behalf of a company) and the system might be through multiple smart devices such as mobile phones, tablets, laptops, etc. These will give rise to a large amount of data from processes, products, communication interactions and business services systems. Here emotional information might be identified through communication flows and peer interactions intensity which will be then translated into emotional evidences to the emotions-oriented supervision system. In addition, the work presented in this paper might contribute to the future developments of IoT in what concerns network context awareness and distributed intelligence problem solving. 


\section{$3 \quad$ Related Literature}

\subsection{Collective Emotions in the Collaborative Networks Context}

Collective emotions have been defined in a relatively general way as emotions that are shared by large numbers of individuals in a certain society [6] while group-based emotions are defined as emotions that are felt by individuals as a result of their membership in a certain group or society [7]. According to Bar-Tal, et al. [8], both concepts suggest that individuals may experience emotions, not necessarily in response to their personal life events, but also in reaction to collective or societal experiences in which only a part of the group members have taken part. But while the former concept suggests that group members may share the same emotions for a number of different reasons, the latter refers only to emotions that individuals experience as a result of identifying themselves with their fellow group members [8].

Emotions are undeniably present in Collaborative Networks, because they are composed of people (representing the $\mathrm{CN}$ member organization) interacting, collaborating and sharing common goals. Each participant brings their own emotional tendencies to the network, and the composition and interaction of those emotions produce an emotional energy that goes beyond the tendencies of individual members. On the other hand, individual members may also experience emotions in reaction to the collective emotion shared by the collaborative network.

In this context, it is interesting to inquire to what extent collective emotions influence the normal operation of CNs.

\subsection{Product-Servicing Network - GloNet Network}

GloNet focuses on collaborative environments for networks of SMEs involved in highly customized and service-enhanced products. The project aims at supporting the notion of glocal enterprise with value creation from global networked operations and involving product-service linkage, and management of distributed manufacturing units, in collaboration with customers and local suppliers (co-creation) [2, 9].

Further to service-based enhancement, there is a growing trend in manufacturing to move towards highly customized products, ultimately one-of-a-kind, which is reflected in the term mass customization[1]. In fact, and according to Piller [10], mass customization refers to a customer co-design process of products and services which meet the needs/choices of each individual customer with regard to the variety of different product features. Important challenges in such manufacturing contexts can be either obtained from the requirements of complex technical infrastructures, solar parks, intelligent buildings, etc.

The guiding use case in GloNet is focused on the production and lifecycle support of solar energy parks. The norm of operation in this industry is that of one-of-a-kind production. The results (products and services) are typically delivered through complementary competences shared between different project participants (organizations can range from mechanical and electrical companies to software product development enterprises in the area).A key challenge is the design and delivery of multi-stakeholder complex services along the product life cycle (typically 20 years). 


\subsection{Business Scenarios}

The development of business scenarios is an important technique that helps in better characterizing requirements, identifying and understanding business needs, and thus provides important inputs for the next phase of the emotions-oriented supervision system development: the design of the system architecture [11].

Although the concept is not precisely defined in the literature, the adopted notion here is that a business scenario represents a significant business need or problem in the target domain. In other words, it provides a reasonably extensive description of a business problem, which enables individual requirements to be viewed in relation to one another in the context of the overall use case / target domain [12].

Taking into consideration that GloNet aims at designing and developing support environments for SME networks, a number of networked structures based on the foundations of collaborative networks [13] are identified: (i) Long-term strategic alliances; (ii) Customer related communities; and (iii) Goal-oriented networks. For the business scenario developed in this paper the focus will be on the Long-term strategic alliances, which typically involve product/project designers, manufacturers, service providers, and some support entities, configuring a kind of virtual organizations breeding environment (VBE). A VBE represents an association of organizations and a number of related supporting institutions, adhering to a base long term (formal or informal) cooperation agreement, and adopting common operating principles and infrastructures, with the main goal of increasing their preparedness towards rapid configuration of goaloriented networks (Virtual Organizations/Virtual Enterprises - VO/VE).

In this way, a business scenario to supervise collective emotions in the context of the GloNet network was considered and developed. The following main elements are considered: (i) Description and purpose; (ii) Goals, outcomes and main features, (iii) Environment and actors; (iv) Details on actors, roles and responsibilities; and (v) Business processes. In addition to tables and textual descriptions, the following formalisms are adopted to help characterizing the business scenario: $i^{*}$ (i-star) to describe actors, individual and common goals, tasks and their inter-relationships[14]; and BPMN - to represent business processes[15].

\section{Business Scenario: Collective Emotions Supervision Services}

\subsection{Description and Purpose}

The purpose of this scenario is to explore the feasibility of supervising collective emotions in the context of product-servicing networks. The main idea underneath this scenario is to illustrate how "emotional issues" of collaboration might be handled and supported by ICT.

Supervising the emotional interactions within the network will provide multimodal emotional input for achieving awareness of the participants as well as the collective emotional state. The supervision system should offer mechanisms to perceive what is not emotionally working and, with or without the administrator intervention, make the necessary adjustments to promote the level and "health" of collaboration. 


\subsection{Goals, Outcomes and Main Features}

Table 1. Goals, outcomes and main features of the collective emotions supervision services

\begin{tabular}{|c|c|c|c|}
\hline Goals & Description & Outcomes & Main Features \\
\hline $\begin{array}{l}\text { Monitor } \\
\text { network } \\
\text { collective } \\
\text { emotions }\end{array}$ & $\begin{array}{l}\text { Monitoring all the } \\
\text { participants' interactions, } \\
\text { seeking for emotional } \\
\text { anomalies. These } \\
\text { malfunctions might } \\
\text { occur when participants } \\
\text { are socializing, } \\
\text { negotiating a new } \\
\text { business opportunity or } \\
\text { when co-working in a } \\
\text { project. }\end{array}$ & $\begin{array}{l}\text { A service that } \\
\text { provides mechanisms } \\
\text { to identify and } \\
\text { monitor the } \\
\text { emotional state of the } \\
\text { network. This service } \\
\text { will provide } \\
\text { emotional } \\
\text { information } \\
\text { according to the } \\
\text { overall state of the } \\
\text { network and will } \\
\text { support an alert } \\
\text { mechanism } \\
\text { whenever something } \\
\text { unusual is detected. }\end{array}$ & $\begin{array}{l}\text { - Mechanisms to collect } \\
\text { and configure member } \\
\text { emotional evidences. } \\
\text { - Mechanisms to identify } \\
\text { and characterize } \\
\text { collective emotions } \\
\text { accordingly. } \\
\text { - Mechanisms to } \\
\text { scrutinize all } \\
\text { interactions looking for } \\
\text { emotional flaws. } \\
\text { - Alerts are fired when } \\
\text { changes in the } \\
\text { emotional state are } \\
\text { noticed. }\end{array}$ \\
\hline $\begin{array}{l}\text { Collective } \\
\text { emotion } \\
\text { fault } \\
\text { analysis }\end{array}$ & $\begin{array}{l}\text { After detecting that } \\
\text { something is not properly } \\
\text { working, a first analysis } \\
\text { of the occurrence, } \\
\text { identifying the emotional } \\
\text { fault, should be done. }\end{array}$ & $\begin{array}{l}\text { A service that } \\
\text { provides mechanisms } \\
\text { to conduct a } \\
\text { comprehensive } \\
\text { diagnosis in order to } \\
\text { identify the } \\
\text { emotional fault. }\end{array}$ & $\begin{array}{l}\text { - Mechanisms to identify } \\
\text { and characterize the } \\
\text { detected emotional } \\
\text { anomaly. } \\
\text { - Delivery of the } \\
\text { identified emotional } \\
\text { fault. }\end{array}$ \\
\hline $\begin{array}{l}\text { Suggest } \\
\text { healing } \\
\text { actions }\end{array}$ & $\begin{array}{l}\text { Once identified the } \\
\text { emotional problem, a } \\
\text { healing process is } \\
\text { suggested with the aim to } \\
\text { restore the emotional } \\
\text { state of the network to } \\
\text { normalcy. }\end{array}$ & $\begin{array}{l}\text { A service that } \\
\text { provides healing } \\
\text { actions to the } \\
\text { diagnosed emotional } \\
\text { fault. }\end{array}$ & $\begin{array}{l}\text { - Mechanisms to evaluate } \\
\text { and analyze the } \\
\text { "situation" and assess its } \\
\text { potential impact on the } \\
\text { network. } \\
\text { - Creation of an action } \\
\text { plan to heal the } \\
\text { identified problem. } \\
\text { - Healing action logs. }\end{array}$ \\
\hline $\begin{array}{l}\text { Suggest } \\
\text { preventive } \\
\text { actions }\end{array}$ & $\begin{array}{l}\text { A continuous assessment } \\
\text { of the possible future } \\
\text { emotional conflicts } \\
\text { among participants is } \\
\text { assured by suggesting } \\
\text { preventive actions. }\end{array}$ & $\begin{array}{l}\text { A service that } \\
\text { predicts potential } \\
\text { conflicts or tension } \\
\text { inside the network. It } \\
\text { aims to suggest } \\
\text { preventive actions } \\
\text { for the sake of the } \\
\text { network emotional } \\
\text { equilibrium. }\end{array}$ & $\begin{array}{l}\text { - Mechanisms to evaluate } \\
\text { and analyze the possible } \\
\text { emotional conflicts and } \\
\text { assess its potential } \\
\text { impact on the network. } \\
\text { - Creation of an action } \\
\text { plan to prevent the } \\
\text { potential problem. } \\
\text { - Preventive action logs. }\end{array}$ \\
\hline
\end{tabular}




\subsection{Environment, Actors and Their Roles}

This scenario envisages the long term strategic alliances (represented as VBE). The involved actors may be individuals and/or organizations that can play the following roles:

VBE Administrator. The VBE Administrator is responsible to supervise the collaborative health of the network by taking the necessary decisions in order to ensure the collective emotional equilibrium.

VBE Member. VBE Members are responsible to make emotions evidences available to the VBE Administrator allowing in this a proper emotions supervision.

VBE Emotions Critical Situation Manager. The VBE Emotions Critical Situation Manager is responsible to diagnose and propose healing solutions whenever the VBE Administrator is informed by the monitoring system that an emotional anomaly occurred. It is also responsible to suggest preventive measures whenever the VBE Administrator perceives a potential thread in the emotional state of the network.

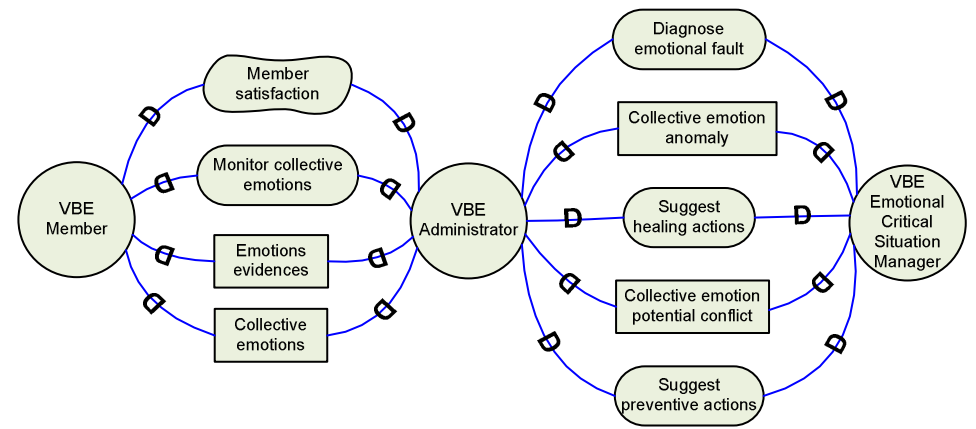

Fig. 1. i* Strategic Dependency Model for Collective Emotions Supervision

\subsection{Details on Actors, Roles and Responsibilities}

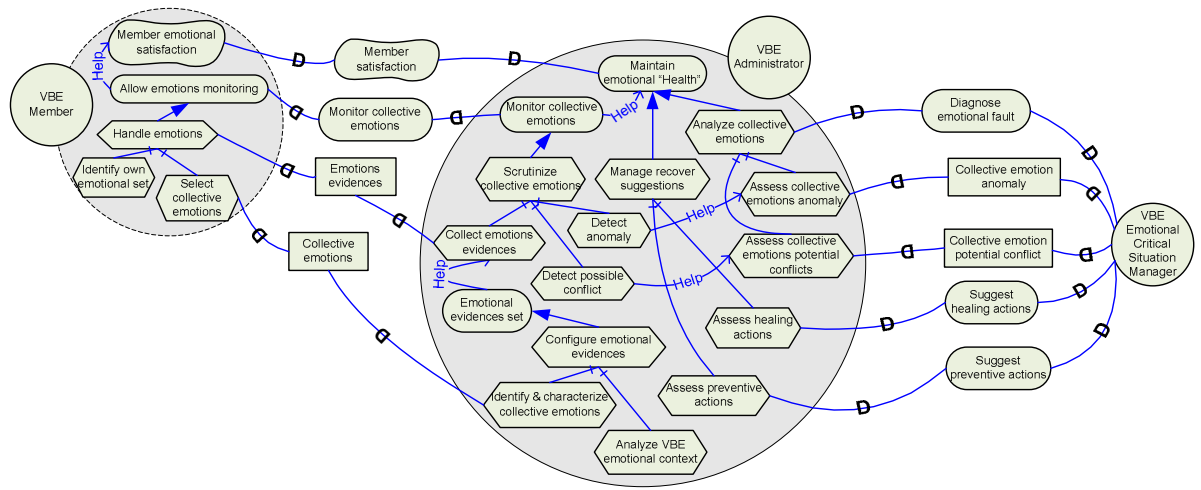

Fig. 2. i* Strategic Rationale Model for Collective Emotions Supervision (partial view 1) 


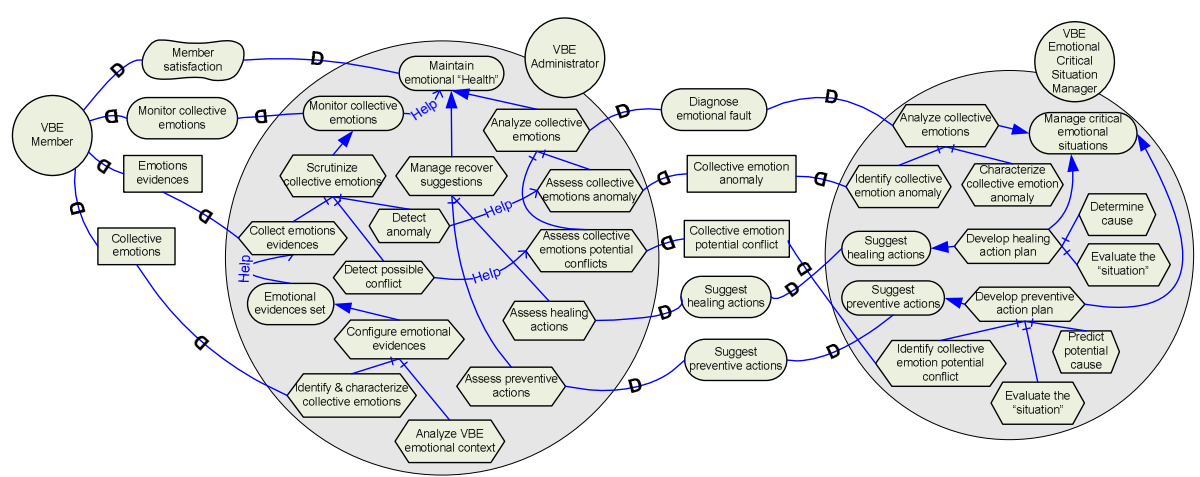

Fig. 3. $i^{*}$ Strategic Rationale Model for Collective Emotions Supervision (partial view 2)

\subsection{Business Processes}

The collective emotions supervision services scenario envisages the following main business processes:

1) Collective emotions characterization and evidences configuration process

2) Collective emotions monitoring process

3) Collective emotion anomaly diagnosis process

4) Healing actions process

5) Preventive actions process.

Collective emotions characterization and evidences configuration process. This process is conducted by the VBE Administrator and interacts with the VBE Members in order to identify and characterize the collective emotions associated to the VBE. In a second phase of the process the VBE Administrator identifies and configures what are the emotional evidences necessary to keep under monitoring in order to maintain the emotional health of the VBE (Fig. 4).

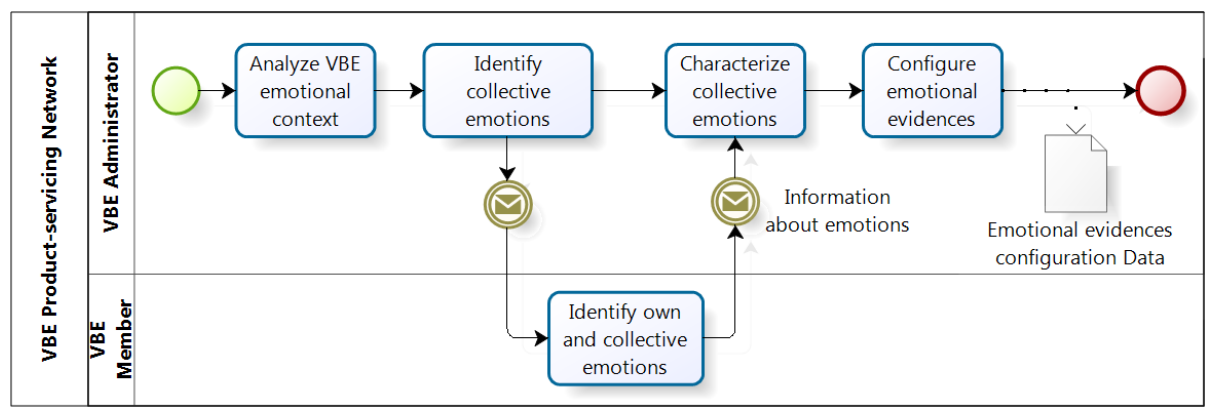

Fig. 4. BPMN diagram of collective emotions characterization and evidences config process

Collective Emotions Monitoring Process. This business process, conducted by the VBE Administrator, comprises the continuous monitoring of emotion evidences 
within a VBE and, when an anomaly that puts in jeopardy the emotional "health" of the network is detected alerts are triggered (Fig. 5).

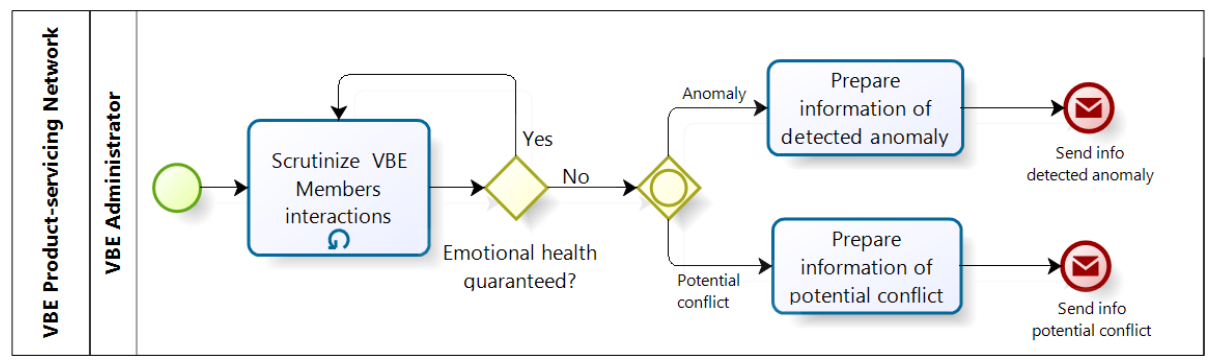

Fig. 5. BPMN diagram of collective emotions monitoring process

Collective Emotion Anomaly Diagnosis Process. This process, which is activated by the monitoring process whenever an anomaly is detected, is carried out by the VBE Emotional Critical Situation Manager and aims to identify and characterize and finally deliver the emotion anomaly (Fig. 6).

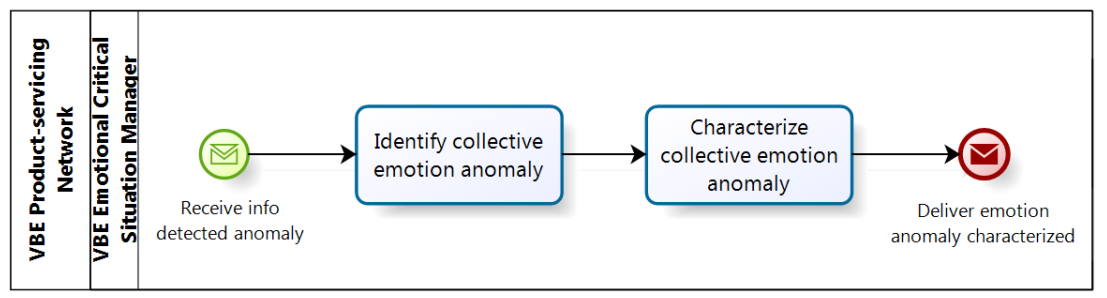

Fig. 6. BPMN diagram of the collective emotion anomaly diagnosis process

Healing Actions Process. This process is activated, with a message containing the characterized emotion anomaly, to the VBE Emotional Critical Situation Manager which is in charge of developing a healing action plan and delivers it to the VBE Administrator. The latter, evaluates the suggested action plan and implements the actions accordingly. Finally the VBE Members are informed (Fig. 7).

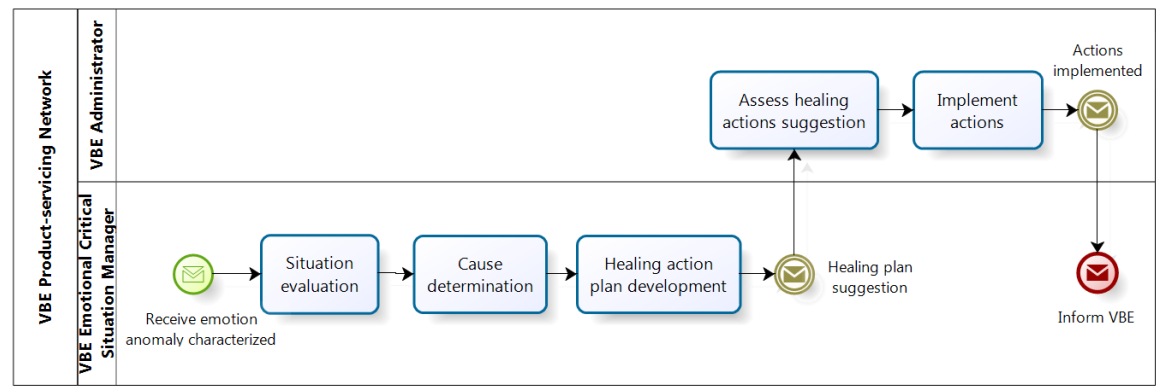

Fig. 7. BPMN diagram of the healing actions process 
Preventive Actions Process. This process, which is activated by the monitoring process whenever a potential conflict is detected, is carried out by the VBE Emotional Critical Situation Manager which firstly identifies the collective emotion potential conflict, evaluates the situation and judges if the detected potential conflict is a thread to the emotional health of the network. If the decision is positive, then a preventive plan is developed and delivered to the VBE Administrator to be implemented. If the decision is negative, i.e., if the identified potential conflict does not put in jeopardize the emotional well being of the network then the process is terminated (Fig. 8).

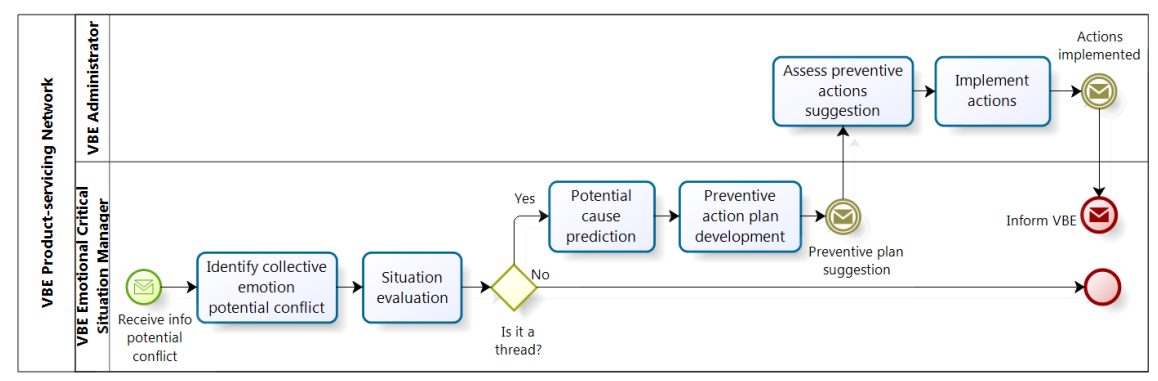

Fig. 8. BPMN diagram of the preventive actions process

\section{$5 \quad$ Conclusions and Future Work}

Product-servicing networks of SMEs aiming at develop customizable servicedenhanced products through the involvement of customers in the creation of product and services (co-creation) are being developed in the GloNet project. Such collaborative networks incorporate global networks of manufacturers and local supply chains in order to attack global business opportunities.

Managing these networks is per se a great challenge, especially because several types of conflicts might arise among partners which might lead to a tension environment. This paper addresses collective emotions as potential drivers to generate conflicts in the GloNet network and presents a business scenario of a supervision system consisting on services to monitor, identify and heal the emotional state of the product-servicing collaborative network.

This work intends to understand what should be the requirements to design and develop an emotions-oriented supervision system in collaborative networks. As such it represents only the design phase of the research project. Future work is planned on building a conceptual model of collective emotions in collaborative networks as well as building a conceptual framework aimed at developing a working definition of the involved concepts and their relationships, developing the purposed processes and validating the system.

Acknowledgments. This work has been supported by the Collaborative Networks and Distributed Industrial Systems (CoDIS) Research Group of Uninova and partly by the GloNet project funded by the European Commission. 


\section{References}

1. Pollard, D., Chuo, S., Lee, B.: Strategies for Mass Customization. Journal of Business \& Economics Research 6(7), 10 (2008)

2. Camarinha-Matos, L.M., Afsarmanesh, H., Koelmel, B.: Collaborative Networks in Support of Service-Enhanced Products. In: Camarinha-Matos, L.M., Pereira-Klen, A., Afsarmanesh, H. (eds.) PRO-VE 2011. IFIP AICT, vol. 362, pp. 95-104. Springer, Heidelberg (2011)

3. Kerr, B.A.: Connecting Emotional Intelligence to Success in the Workplace (2009)

4. Glinow, M.A.V., Shapiro, D.L., Brett, J.M.: Can we talk, and should we? Managing emotional conflict in multicultural teams. Academy of Management Review 29(4), 578-592 (2004)

5. Sundmaeker, H., et al. (eds.): Vision and Challenges for Realising the Internet of Things, CERP-IoT. European Commission - Information Society and Media, Luxembourg (2010)

6. Stephan, W.G., Stephan, C.W.: An integrated threat theory of prejudice. In: Oskamp, S. (ed.) Reducing Prejudice and Discrimination, pp. 225-246. Erlbaum, Hillsdale (2000)

7. Smith, E.R.: Social identity and social emotions: Toward new conceptualization of prejudice. In: Mackie, D.M., Hamilton, D.L. (eds.) Affect, Cognition and Stereotyping: Interactive Processes in Group Perception, pp. 297-315. Academic Press, San Diego (1993)

8. Bar-Tal, D., Halperin, E., de Rivera, J.: Collective Emotions in Conflict Situations: Societal Implications. Journal of Social Issues 63(2), 441-460 (2007)

9. Camarinha-Matos, L.M., Macedo, P., Ferrada, F., Oliveira, A.I.: Collaborative Business Scenarios in a Service-Enhanced Products Ecosystem. In: Camarinha-Matos, L.M., Xu, L., Afsarmanesh, H. (eds.) PRO-VE 2012. IFIP AICT, vol. 380, pp. 13-25. Springer, Heidelberg (2012)

10. Piller, F.T.: Mass Customization: Reflections on the State of the Concept. The International Journal of Flexible Manufacturing Systems 16(4), 313-334 (2004)

11. Ferrada, F., Camarinha-Matos, L.M.: Emotions in Collaborative Networks: A Monitoring System. In: Camarinha-Matos, L.M., Shahamatnia, E., Nunes, G. (eds.) DoCEIS 2012. IFIP AICT, vol. 372, pp. 9-20. Springer, Heidelberg (2012)

12. OpenGroup. Business Scenarios (2011), http: / / pubs . opengroup.org/ architecture/togaf7-doc/arch/p4/bus_scen/bus_scen.htm (cited April 5, 2012)

13. Camarinha-Matos, L.M., Afsarmanesh, H. (eds.): Collaborative Networks: Reference Modeling. Springer, New York (2008)

14. Yu, E.S.K.: Modelling Strategic Reltionships for Process Reengineering, Department of Computer Science, University of Toronto, Toronto (1995)

15. OMG, Business process modeling notation. Version 1.1 (2008) 